\title{
Performance Comparison of VSI Based DSTATCOM and ZSI Based DSTATCOM in A Distribution System Network
}

\author{
${ }^{1}$ Ruban Preet Kaur, ${ }^{2}$ Parag Nijhawan \\ ${ }^{12,}$ Department of Electrical and Instrumentation Engg. Thapar University, Patiala-147004, Punjab
}

\begin{abstract}
D-STATCOM (Distribution Static Compensator) is a shunt device which is generally used to improve power quality of distribution systems. It is a device applied for correcting power factor, maintaining constant distribution voltage and mitigating current harmonics in a distribution network. In this paper, effort has been made to use ZSI based D-STATCOM in distribution system and its performance has been compared to VSI based DSTATCOM. The MATLAB/SIMULINK models have been developed to draw the conclusions.
\end{abstract}

Keywords: FACTS devices, DSTATCOM, Z-Source Inverter.

\section{Introduction}

Power quality (PQ) problems mainly include unbalance voltage and current, flicker, harmonics and power interruption. These power quality problems leads to abnormal operations of facilities and tripping of protection devices. The maintenance and improvement of power quality is a matter of concern present days. The term "load balancing" explains to balance unbalanced load and correct load power factor nearly unity [1]. Load compensation is very important in context of today's load. So, the FACTS devices are introduced to electrical system in order to enhance the power quality of the system. Types of FACTS device are DVR, UPQC, STATCOM, DSTATCOM, UPFC, SVC, SSG, TCR, TSC, TSR, SSSC and etc. STATCOM used in distribution system is termed as DSTACOM (Distribution-STACOM). D-STATCOM is a high speed and control reactive power, to provide voltage stabilization and flicker suppression .A DSTATCOM includes a Voltage Source converter (VSC) and a DC link capacitor connected in shunt [2], capable of generating and /or absorbing reactive power. In this paper we present simulation results with DSTATCOM using ZSI and VSI in various cases for comparison of their performance.

\section{Basic Configuration And Principle Of Dstatcom}

DSTATCOM is utilized to mitigate the current harmonics in distribution system and also balance them in addition to compensating reactive power. In addition it also leads to reduction in voltage fluctuations at the PCC (point of common coupling) [3].

DSTATCOM system is comprised of three main parts:

a. VSC,

b. A set of coupling reactors and

c. Controller.

The basic principle of a DSTATCOM installed in a power system is the generation of a controllable ac voltage source by a voltage source inverter (VSI) [4]in addition with dc capacitor (storage device). The ac voltage source appears behind a transformer leakage reactance. The active and reactive power transfer between the power system and the DSTATCOM is caused by the voltage difference across this reactance. The DSTATCOM is connected to the distribution power networks at a PCC (point of common coupling) [5], where the voltage-quality is a matter of concern. All required voltages and currents are measured and are fed into the controller in order to compare with the commands [6]. The controller then performs feedback control and outputs a set of switching signals to drive the main semiconductor switches (IGBT's) of the power converter accordingly. The basic structure of the DSTATCOM is shown in Fig1. 


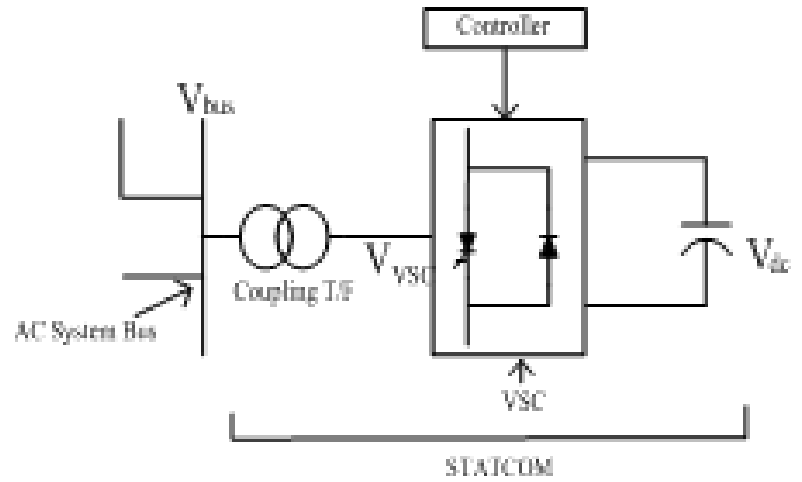

Fig1: DSTATCOM

\section{Voltage Source Convertors (VSC):}

A voltage-source converter is a power electronic device that generates a sinusoidal voltage of required magnitude, frequency and phase angle. These are widely used in adjustable-speed drives, but can also be used to mitigate voltage dips. The VSC is used to either completely replace the voltage or to inject the 'missing voltage'. The 'missing voltage' is the difference between the nominal voltage and the actual. The converter is normally based on some kind of energy storage, which will supply the converter with a DC voltage like capacitor. The solid-state electronics in the converter is then switched to get the desired output voltage. VSC is also used for power quality issues, e.g. flicker and harmonic.

\section{Z-Source Inverter:}

ZSI can boost the low DC power to a specified high voltage, and the two switches of the same bridge arm can conduct at the same time without requirement of a step up transformer. ZSI can reduce the harmonic content because of the dead zone setting, and improve the quality of the power conversion. The commonly used three-phase inverter cannot provide pathways for the zero sequence current which is generated by un-balanced load; it is only suitable for balanced load. In this bridge arm constitutes midline and then eliminates the need of the midpoint transformer when the load is unbalanced, reduces the volume and weight of the system. It has Xshaped impedance network on its DC side, which interfaces the source and inverter. The impedance network composed of split inductors and two capacitors. The supply can be DC voltage source or DC current source or AC source. It can be current source type or voltage source type. The DC source can be a battery, diode rectifier, PV cell, an inductor, a capacitor etc [7]. Switches used in the converter can be a combination of switching devices and anti-parallel diodes.

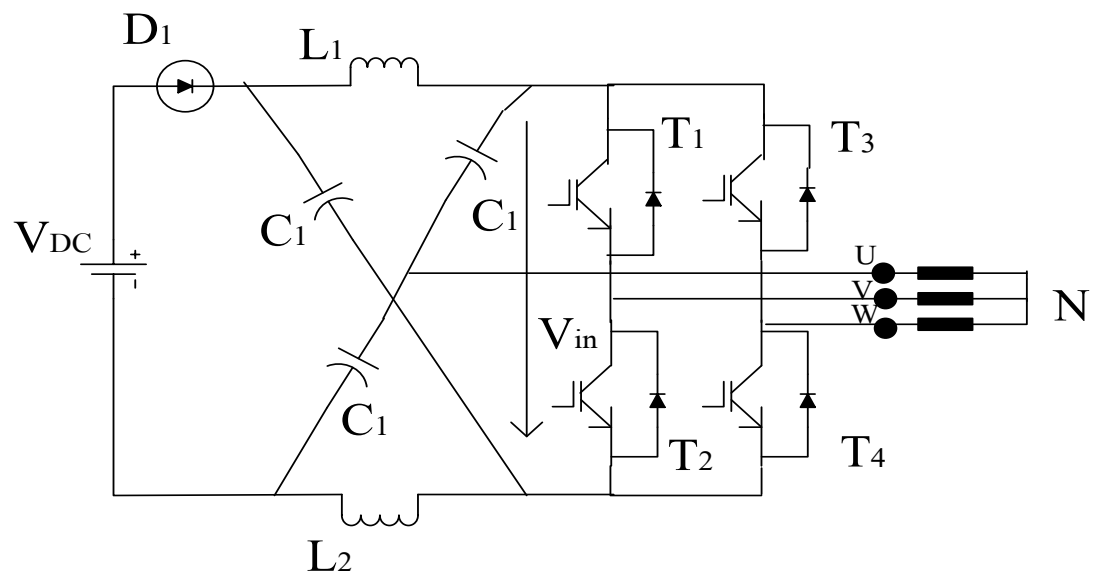

Fig2: ZSI 


\section{Block Diagrams}

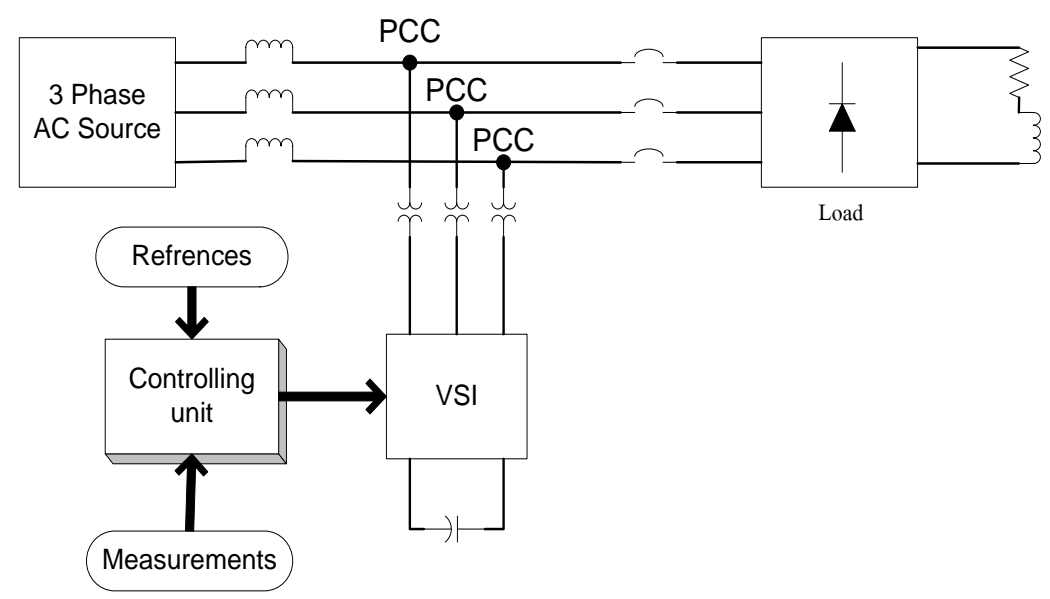

Fig3: DSTATCOM with VSI

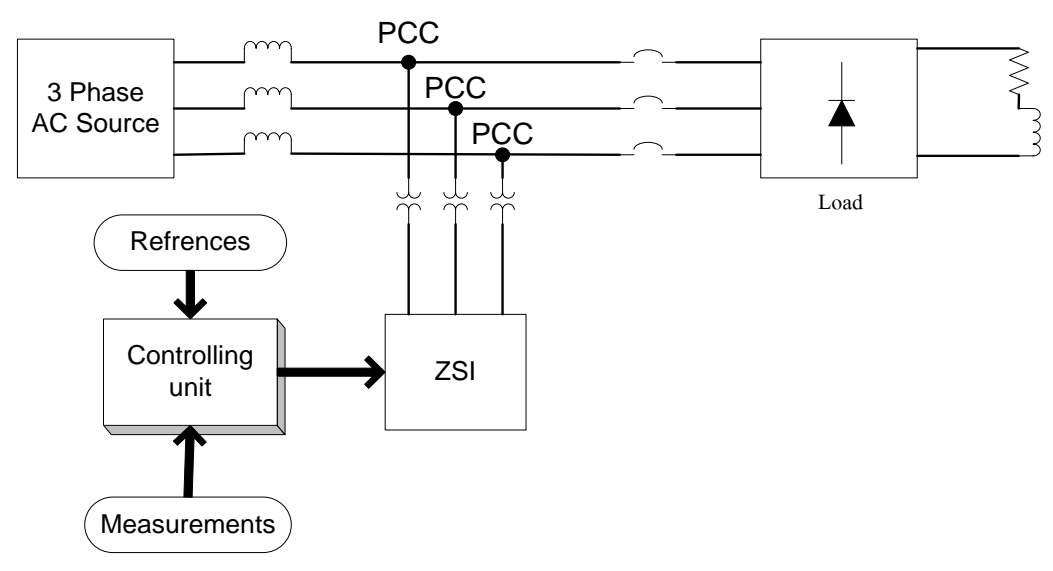

Fig4: DSTATCOM with ZSI

\section{Case I: Reduction in THD level.}

\section{Results}
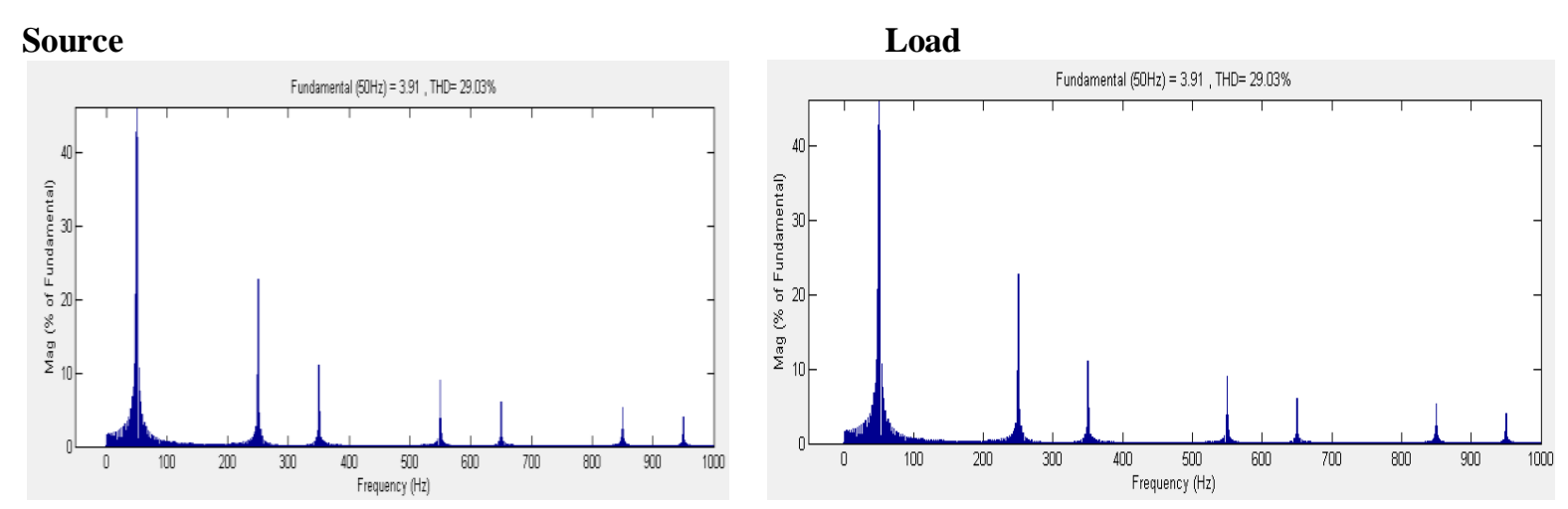


\section{DSTATCOM with VSI}

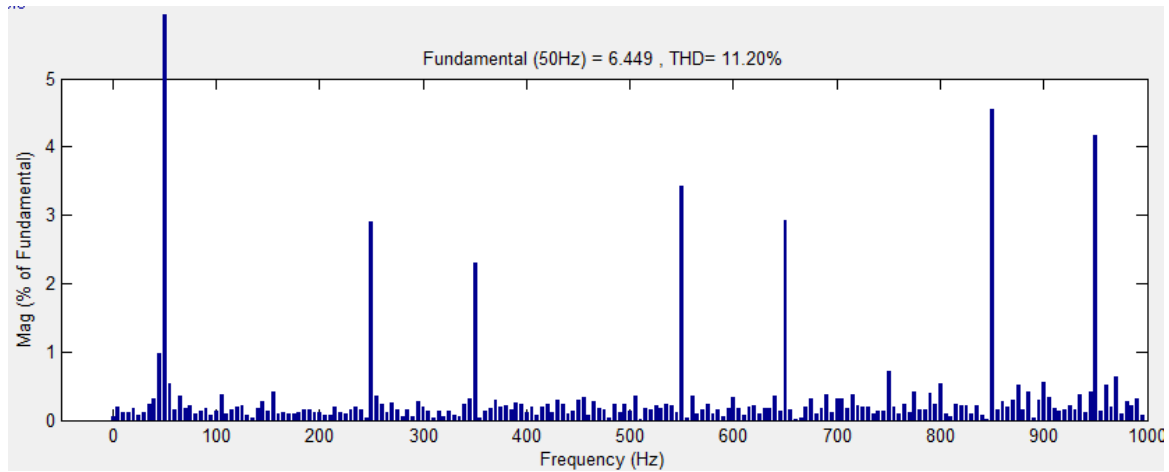

\section{DSTATCOM with ZSI}

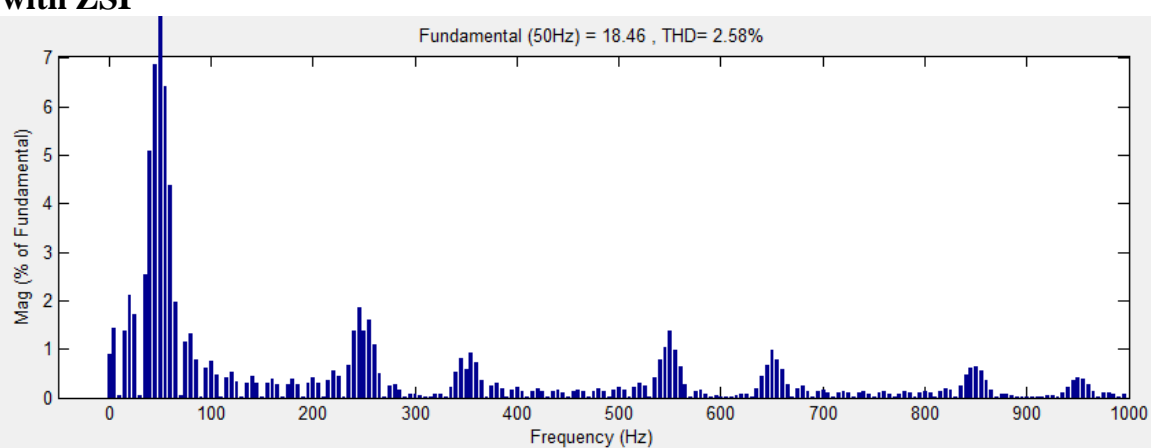

\section{Case II: Power factor Improvement}

Power factor in distribution system with Inductive load can be improved by implementing DSTATCOM. Here performance of DSTATCOM with VSI and that of with ZSI are compared in order to find out better combination for power factor improvement. Distribution system used here without DSTATCOM shows power factor of $\mathbf{0 . 9 5 0 6}$ which is improved to $\mathbf{0 . 9 5 6 7}$ when DSTAT with VSI is employed but when ZSI based DSTAT is used it improves power factor to $\mathbf{0 . 9 9 7}$. This shows that if power factor improvement is required to more extent than ZSI based DSTAT will be the preferred device.

\section{Case III: Load Balancing}

The performance of DSTATCOM with VSI or ZSI is compared for load balancing.

The supply currents are balanced and in phase at all conditions [8]. At $0.1 \mathrm{sec}$ load is changed to two phase load, at $0.2 \mathrm{sec}$ load changes to single phase and at $0.4 \mathrm{sec}$ load gets disconnected. And all phases of load are applied again at $0.45 \mathrm{sec}$.

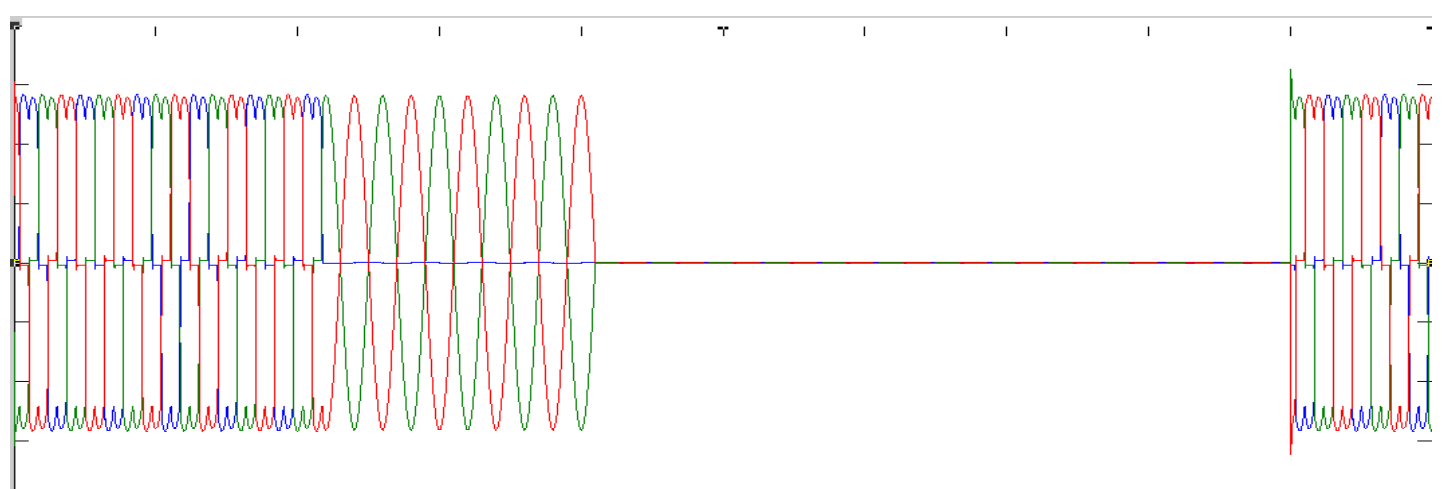

Fig5: Load Current $\stackrel{-}{\left(I_{\text {load }}\right)}$ Waveforms 


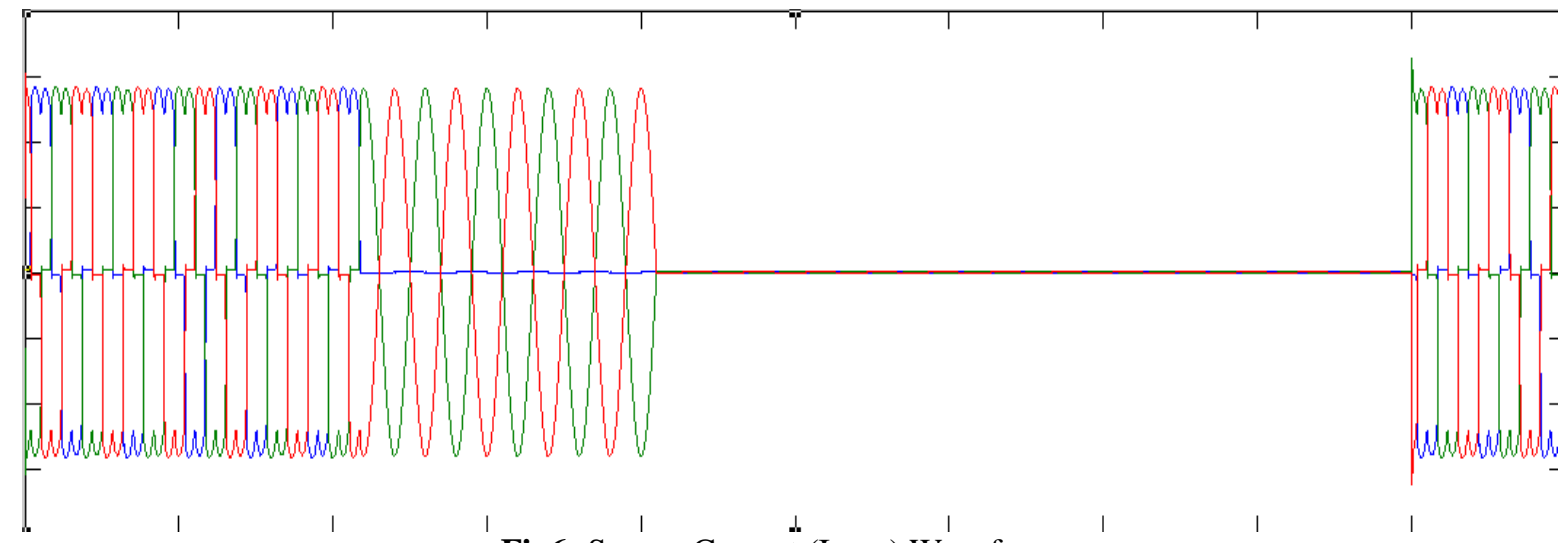

Fig6: Source Current $\left(\mathrm{I}_{\text {source }}\right)$ Waveforms

A. DSTATCOM with VSI. The results obtained from the simulation models are shown in Fig7.

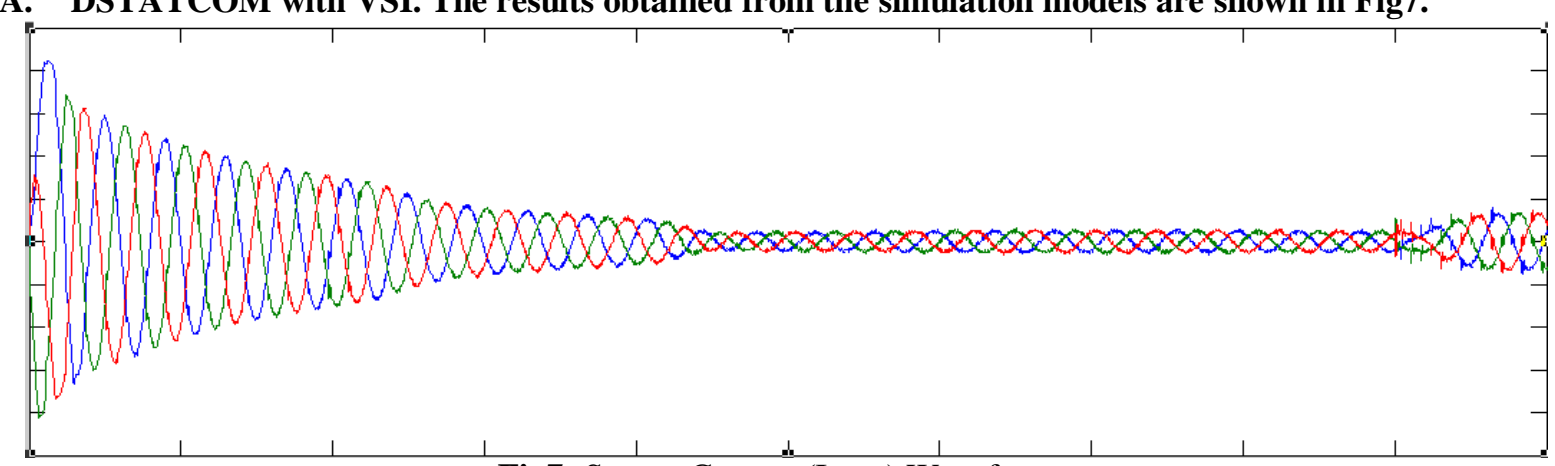

Fig7: Source Current ( $\left.\mathrm{I}_{\text {source }}\right)$ Waveforms

B. DSTATCOM with ZSI. The results obtained from the simulation models are shown in Fig8.

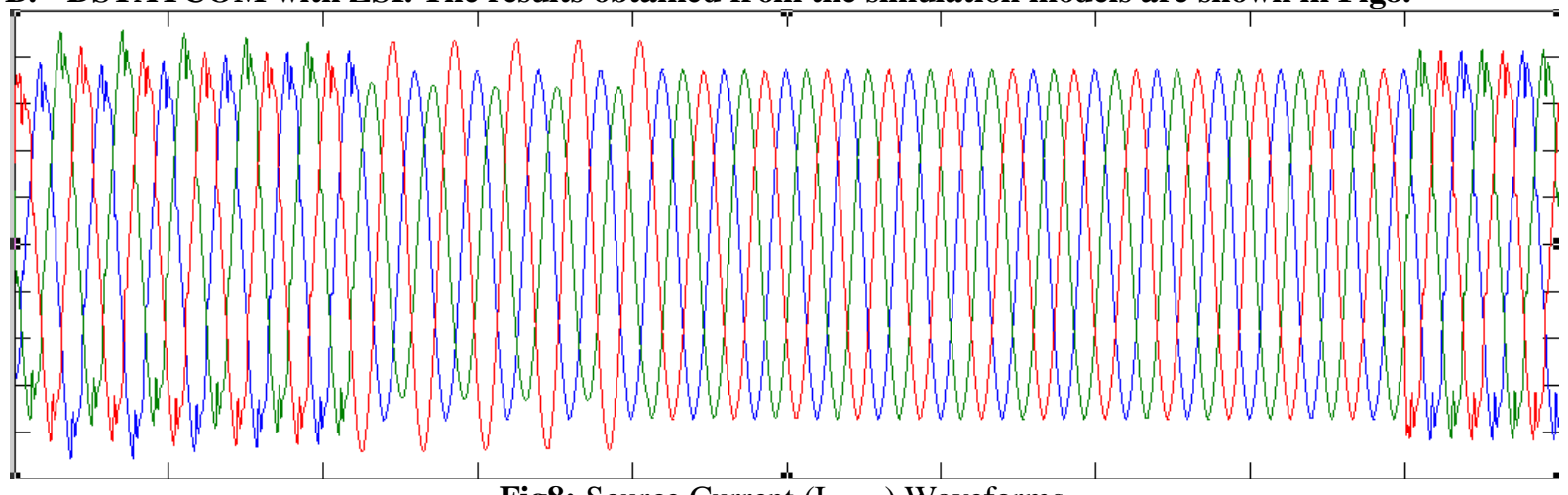

Fig8: Source Current $\left(\mathrm{I}_{\text {source }}\right)$ Waveforms

\section{Conclusions}

In this paper, the THD reduction in source current is more in the case of DSTATCOM based on ZSI as compared to that of DSTATCOM based on ZSI, similarly power factor improvement is comparatively better in ZSI based DSTATCOM than VSI based DSTATCOM. Source current is compensated relatively well in case of ZSI based DSTATCOM as compared to VSI based DSTATCOM. As per waveforms shown above it is depicted that source current waveforms are more sinusoidal and balanced in ZSI based DSTATCOM compensated distribution system as compared to that observed in VSI based DSTATCOM compensated distribution system.

\begin{tabular}{|lll|}
\hline Line Impedance $\quad-\mathrm{R}_{\mathrm{s}}=0.01 \Omega, \mathrm{L}_{\mathrm{s}}=2 \mathrm{mH}$ & \\
Ripple Filter $\quad-\mathrm{R}_{\mathrm{f}}=5 \Omega, \mathrm{C}_{\mathrm{f}}=10 \mu \mathrm{F}$ & \\
DC Bus Capacitor $-500 \mu \mathrm{F}$ & - & \\
$\mathrm{DC} \quad$ Bus Voltage & & \\
AC Line Voltage & $-415 \mathrm{~V}, 50 \mathrm{~Hz}$ \\
Non-Linear Load & - Universal Bridge & \\
\hline
\end{tabular}




\section{References}

[1]. Wei-Neng Chang, Kuan-DihYeh, "Design and implementation of DSTATCOM for fast load compensation of Unbalanced Loads", Journal of Marine Sci. and Tech., Vol. 17, No. 4, pp. 257-263(2009)

[2]. D. Masand, S. Jain, G. Agnihotri, "DSTATCOM performance under linear and non linear current regulation methods", J. Electrical Systems 4-1 (2008): 91-105.

[3]. Parag Nijhawan, Ravinder Singh Bhatia, and Dinesh Kumar Jain, “Application of PI controller based DSTATCOM for improving the power quality in a power system network with induction furnace load", SJST, 34 (2), 195-201, Mar. - Apr. 2012.

[4]. R. Indumathi, M. Venkateshkumar, R. Raghvan, "Integration of DSTATCOM based PV cell power in Low Voltage power Distribution Grid", IEEE International Conference on Advances in Engineering, Science and Management (ICAESM-2012) March $30,31,2012$.

[5]. Alpesh Mahavanshi, M.A. Mulla, R. Chudamani, "Reactive power compensation by controlling the DSTATCOM", IJETAE, ISSN 2250-2459, Vol. 2, Issue 11, Nov, 2012.

[6]. G. Murali, A. Manivannan, "Analysis of power quality problems in solar power distribution systems", IJERA, ISSN: 2248-9622, Vol. 3, Issue 2, March-April 2013, pp.799-805

[7]. S. Muthukrishnan, A. Nirmalkumar and G. Murugananth, "Modeling and Simulation of Five Level Inverter based UPFC System", International Journal of Computer Applications, Vol. 12, No.11, January 2011,pp.11-15.

[8]. Bhim Singh, P. Jayaprakash, D.P. Kothari, "New Control Approach for capacitor supported DSTATCOM in 3-Phase four wire distribution system", Electrical Power and Energy Systems 33(2011) 1109-1117. 